\title{
Mara Glozman y Daniela Lauria Voces y ecos. Una antología de los debates sobre la lengua nacional (Argentina, 1900- 2000). Buenos Aires, Ediciones Biblioteca Nacional, Cabiria, 2012
}

\author{
José Fernando Chapa Barrios \\ fernandochapabarrios@gmail.com
}

La lengua es el vehículo de la comunicación y el mecanismo que posibilita las relaciones sociales en todos sus niveles. Por eso ocupa un lugar central entre los factores que constituyen las ideas de identidad nacional. En muchos sentidos, las diversas ideologías sobre la lengua tienen un tránsito paralelo al de las ideologías políticas y las corrientes de pensamiento sobre la nación. La relación entre lengua y nación y los modos en que esta es pensada han suscitado constantes polémicas y debates que han adquirido formas diferentes dependiendo del periodo histórico y del lugar en que ocurren. Voces y ecos. Una antología de los debates sobre la lengua nacional, de Mara Glozman y Daniela Lauria, ofrece una perspectiva del desarrollo de las polémicas sobre lo que ellas llaman "la querella del idioma" en Argentina durante el siglo Xx.
El libro presenta una selección de fragmentos de 43 textos que dan cuenta de la evolución de las preocupaciones en torno a la lengua nacional argentina en diversos periodos del siglo xx. La antología se organiza en ocho secciones. La primera es una introducción en la que las autoras describen las razones que las motivaron a reunir los debates sobre la lengua argentina en el siglo pasado; principalmente, la ausencia de otros trabajos de esta índole, en contraste con la amplia documentación de este tipo de debates durante el siglo XIX. Asimismo, ofrecen un resumen del desarrollo de las polémicas decimonónicas sobre la lengua, los factores que las ocasionaron, los grupos que participaron en ellas y los ejes temáticos alrededor de los cuales se centraron. El foco de la antología es, sin duda, la relación entre la historia política argentina y las diversas ideolo- 
gías sobre la lengua. La introducción presenta el contexto histórico que da pie a las polémicas lingüísticas particulares del siglo xx e invita a leer los textos reunidos en su dimensión histórica.

Las siguientes siete secciones contienen los textos reunidos. Cada sección presenta entre cinco y ocho textos y representa aproximadamente una década del siglo pasado. De igual modo, en cada sección los textos están organizados alrededor de los temas que caracterizaron al periodo. Sin embargo, es clara la preferencia por la organización cronológica, lo que tiene como consecuencia una heterogeneidad temática en el desarrollo de la antología. A su vez, las secciones cuentan con una breve introducción de las autoras que resume la conexión del periodo histórico con las polémicas lingüísticas presentadas y una ficha técnica de la primera edición de las publicaciones.

La primera sección, "Lengua, nación e inmigración”, reúne seis textos de entre 1900 y 1912 que ilustran dos ejes temáticos. El primero, la inmigración como fenómeno social que altera la lengua argentina. El segundo, la controvertida publicación del texto Idioma nacional de los argentinos de Lucien Abeille y la idea de que la lengua hablada en Argentina se diferenciaría del español peninsular de modo tan extremo que terminaría por constituir un idioma completamente distinto. La tesis, contestada ferozmente por Ernesto Quesada y Ricardo Montaner Sans, sigue una lógica que piensa en la lengua como reflejo de la historia política nacional. De modo que, 100 años de independencia política deberían producir una independencia lingüística. Sin embargo, las respuestas a esta idea reducen los indicios de una variedad argentina del español a meros "descuidos de la lengua que se habla". Los fragmentos seleccionados no dejan muy claro cómo definir los criterios que permitirán observar un "idioma argentino". Esta falta de claridad acerca de qué es la lengua y qué medios se usan para hablar de ella es una constante en la mayoría de los textos seleccionados. Una excepción notable la constituye el texto de Tobías Garzón, un fragmento de la introducción a su Diccionario argentino, en el que propone la medición del léxico encontrado en un corpus especializado como modo de acercarse a la variedad argentina del español.

La segunda sección, "Idioma nacional y campos de saber: literatura, filología e instituciones", está conformada por seis textos de entre 1926 y 1933. Reúne textos de Jorge Luis Borges, Roberto Arlt, Vicente Rossi y Amado Alonso, los cuales presentan diversas perspectivas de la len- 
gua nacional desde las instituciones académicas, la incipiente disciplina filológica hispana y los quehaceres literarios. Es especialmente prominente la atención que recibe el tema del argot lunfardo y su recepción en los círculos literarios. De nuevo, en esta sección no hay criterios claros para hablar de la lengua. Los "saberes especializados" echan mano de ideas vagas sobre lo que es y debe ser la lengua de una nación.

La tercera sección, "La lengua y la tesis de las peculiaridades", se centra en los años 1941 a 1943. Reúne seis textos y se enfoca en la tesis de Américo Castro sobre la valoración de ciertas características del español de Argentina que lo hacen distinto al español europeo. Esta valoración es siempre negativa y se concentra en el desprecio al lunfardo y al léxico no considerado culto. La mayoría de los textos seleccionados en esta sección son respuestas, a veces en concordancia y otras en contra de las ideas de Castro. Luis C. Pinto, Vicente Rossi y Jorge Luis Borges atacan la censura de Américo Castro a las peculiaridades de la lengua argentina. Borges propone que no existe problema alguno que deba ser resuelto al encontrar las variedades lingüísticas que forman el español argentino. Sin embargo, como el resto de los textos de la sección, tampoco existe una distinción clara de lo que constituye la variación, dónde se encuentra y qué tan extendida está.

El cuarto apartado, "Lo nacional, lo popular y la cuestión de la lengua”, contiene ocho textos publicados entre 1951 y 1955, que expresan una postura purista sobre la lengua. El ejercicio del purismo empieza a entenderse como acto de "sanción" de la lengua. La responsabilidad de ejercer esta sanción recae en los distintos organismos gubernamentales, las academias y las instituciones escolares. De modo pomposo y sin ofrecer algún tipo de evidencia sobre lo que significan cosas como "barbarismo" o "catástrofe idiomática”, autores como Arturo Capdevilla, Fray Verísimo y Avelino Herrero Mayor dictaminan que existe en Argentina un mal de la lengua que se nota en la propagación de vocablos "incultos", expresiones "incorrectas" y producciones lingüísticas que se describen como "despeñaderos del habla", en palabras de Fray Verísimo (62).

El quinto apartado, llamado "Voseo, literatura y pensamiento nacional", reúne cinco textos publicados entre 1960 y 1964 . Esta es la primera sección que incluye un trabajo de descripción lingüística enfocado en un aspecto específico del español argentino. Se trata del texto de Berta Elena Vidal de Battini, "El español de la Argentina. Estudio destinado a los maestros de las escuelas primarias". 
Es el primer texto de la antología que ofrece información producto de una metodología de estudio lingüístico serio. Además del texto de Vidal de Battini, se documentan diversas opiniones sobre el uso del voseo en el español argentino. Destaca la opinión de Ernesto Sábato, quien argumenta que, al encontrarse el voseo entre los grandes escritores de Argentina, no hay razones para censurar su uso. Se suma el trabajo de Ruth Fernández, que reúne entrevistas a Silvina Bullrich, Jorge Luis Borges, Abelardo Castillo y Roberto Giusti sobre el voseo.

El sexto apartado: "Lengua, cultura nacional y construcción de la argentinidad" se centra en el léxico argentino y el lunfardo. Reúne cinco textos de entre 1973 y 1982 . Esta sección busca en la lengua un elemento distintivo de la argentinidad. Esta necesidad de distinción se acompaña de un nacionalismo institucional que se ve, ya no en la recopilación de voces de escritores, sino en miembros de instituciones académicas como la Academia Argentina de Letras, o del autor del Diccionario de argentinismos de ayer y hoy. De nuevo, destaca un texto de Berta Elena Vidal de Battini sobre la persistencia del léxico español en las islas Malvinas. Este texto es a la vez que un estudio serio sobre la vitalidad léxica, un modo de mostrar cómo la cultura argentina ha prevalecido sobre la influencia inglesa en las islas. El lunfardo, uno de los ejes temáticos que causa mayor ansiedad en los debates sobre la lengua en Argentina, se encuentra presente en la entrevista que Norma Colloca hace a Edmundo Rivero y José Gobello, dos "expertos" sobre el lunfardo.

La última sección, "Unidad/diversidad, defensa de la lengua y Mercosur: Políticas lingüísticas y saberes especializados", es la más ecléctica de la antología. Comprende seis textos de entre 1989 y 1997 . Se centra en la planeación y desarrollo de políticas lingüísticas en el contexto del convenio denominado Mercosur, el cual implicaba la relación entre países con lenguas distintas y hacía necesario tener estructuras legales que normaran sobre la lengua. En torno al acto de normar reflexionan Ofelia Kovacci, de la Academia Argentina de Letras, y Mercedes Isabel Blanco, quien ofrece un diagnóstico acertado sobre las ideologías lingüísticas del purismo y la corrección, así como la artificialidad de los intentos por normar sobre la lengua. Sobre el caso específico de la lengua española en el contexto internacional que ofrece el Mercosur, Elvira Narvaja de Arnoux y Roberto Bein reflexionan en un texto que menciona por primera vez las lenguas indígenas de Argentina y su inclusión en los proyectos de política lingüística. Quizá 
el texto que, desde el saber especializado de la disciplina lingüística, zanja de mejor manera las polémicas expuestas a lo largo de la antología es el de María Beatriz Fontanella de Weinberg, quien presenta la sociolingüística como marco para diferenciar los tipos de variación lingüística y los modos de hablar sobre esta.

Los textos seleccionados en esta antología ofrecen una perspectiva diacrónica del desarrollo de saberes especializados en la lengua. Cada una de las épocas que se presentan en los apartados puede leerse como la respuesta a quién puede hablar sobre la lengua. Queda claro que hay un paso de los miembros de círculos de "cultura”, gremios literarios y académicos a profesionales de la lengua, que han adquirido métodos especializados para analizar los distintos niveles de la lengua y hablar de los fenómenos lingüísticos desde un lenguaje técnico, descriptivo y ajeno de prejuicios lingüísticos. Este paso no es, de ningún modo, absoluto. El surgimiento de una disciplina lingüística no implica la imposibilidad de que individuos no preparados intenten normar o censurar la lengua desde posiciones prescriptivistas. Sin embargo, sí implica el desarrollo de un contrapeso a la pretensión intelectual y un desplazamiento del dominio de lo que Mercedes Isabel Blanco llama "hombres vinculados al ámbito cultural" hacia una técnica de la lengua.

La pregunta "¿quién puede hablar sobre la lengua?" encuentra una respuesta concreta en la expresión ya mencionada de Mercedes Isabel Blanco: "hombres vinculados al ámbito cultural". Si la autora hacía uso del masculino genérico o se refería específicamente a individuos masculinos con el sustantivo hombres, no queda claro, pero la presente antología parece indicar que hay en el desarrollo de los debates sobre la lengua una fuerte dominación masculina. Llama la atención que, de los 38 autores seleccionados, 28 son hombres; dos mujeres aparecen únicamente como periodistas que presentan las voces de otras personas (en su mayoría hombres), tres documentos firmados por instituciones y tan solo cinco mujeres que hablan desde su propia voz. Estas cinco mujeres son todas lingüistas que se han especializado en un saber técnico sobre la lengua. En este sentido, la presente antología parece indicar que los hombres pueden hablar de la lengua y prescribir sobre ella desde un campo cultural y literario sin hacer uso de un lenguaje técnico, mientras que las mujeres, cuando participan en los debates sobre la lengua, lo hacen desde la certeza de la academia y los saberes universitarios. 
En general, Voces y ecos exhibe un panorama completo sobre el modo en que la relación entre lengua y nación es entendida desde perspectivas sumamente diversas. Se complementa con una visión histórica que vincula las opiniones de los autores seleccionados con los momentos específicos del contexto histórico en que escriben. Sin embargo, la disposición en los textos que conforman la antología hace que se pierda el hilo conductor de debates que están organizados alrededor de ciertos ejes temáticos. Las autoras no ofrecen un índice temático ni una guía cronológica de polémicas específicas. En contraste, presentan un desarrollo que se percibe más cercano al del que realmente tuvieron estos debates, de modo que diversos autores reflejan posturas expresadas décadas atrás. Ciertamente, esta visión, incluso a pesar de concluir con textos especializados en la investigación lingüísti- ca, parece sugerir que las polémicas sobre "el problema de la lengua" seguirán encontrando eco en autores del presente y del futuro. En otras palabras, el progreso no parece ser un mecanismo que guíe este tipo de intercambios ideológicos. Habrá que examinar los debates que se conducen actualmente y esperar los futuros para determinar qué tanto hacen eco con los del pasado.

\section{José Fernando Chapa Barrios}

Egresado de la carrera en Lengua y Literaturas Hispánicas en la Facultad de Filosofía y Letras de la UNAM. Está interesado en la sintaxis, la sociolingüística y la variación lingüística. Ha realizado trabajos sobre la duplicación de objeto directo en el español de Chiapas. Le interesa la gramática latina y ha sido profesor adjunto en cursos de latín impartidos en la carrera de Letras Hispánicas y de latín básico en la Biblioteca Nacional. 